Geografia e Ordenamento do Território, Revista Electrónica

Centro de Estudos de Geografia e Ordenamento do Território

http://cegot.org

ISSN : 2182-1267

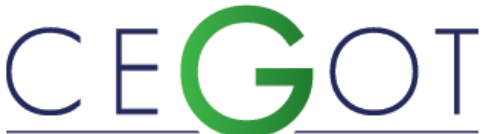

Centro de Estudos de Geografia e Ordenamento do Território

\begin{abstract}
Arruda, CarolinNe
Universidade Federal do Rio de Janeiro, Centro de Ciências Jurídicas e Econômicas, Instituto de Pesquisa e Planejamento Urbano e Regional Av. Horácio Macedo, 끄 2151 - Edifício da Faculdade de Letras Cidade Universitária, Rio de Janeiro - RJ, CEP: 21941-917, Brasil carolinne.arruda@gmail.com
\end{abstract}

\title{
Território e planejamento contemporâneo: análise sobre a abordagem territorial dos PPAs
}

Territory and contemporary planning: analysis on the territorial approach of the PPAs

Referência: Arruda, Carolinne (2017). Território e planejamento contemporâneo: análise sobre a abordagem territorial dos PPAs. Revista de Geografia e Ordenamento do Território (GOT), n.o 12 (dezembro). Centro de Estudos de Geografia e Ordenamento do Território, p. 23-47, dx.doi.org/10.17127/got/2017.12.002

\section{RESUMO}

A problemática regional brasileira consiste em um processo histórico de territorialização desigual do capitalismo e, consequentemente, do poder. Como um processo heterogêneo e complexo, o Estado lidou com a questão de formas diversificadas ao longo do tempo, nem sempre apresentando como resultado a minoração das desigualdades territoriais. Nesse sentido, o objetivo deste artigo é contribuir para o entendimento acerca da responsabilidade do Estado na correção da materialização desigual do poder no território e como a ausência da dimensão territorial dentro das suas ações contribui para o acirramento das desigualdades espaciais brasileiras, tendo como base de análise os três planos plurianuais mais recentes do Governo Federal (PPA 2004-2007, 2008-2001 e 2012-2015).

Palavras-chave: Planejamento; Desigualdade; Desenvolvimento regional; Plano plurianual.

\section{ABSTRACT}

The brazilian regional problem consists in a historical process of unequal territorialization of capitalism an, consequently, of power. As a heterogenous and complex process, the state has handled with the issue in a variety of ways over time, not always resulting in the reduction of territorial inequalities. In this sense, the objective of this article is to contribute 
to the understanding about the responsibility of the State in correct the unequal materialization of power in the territory and how the absence of the territorial dimension inside their actions contributes to the intensification of brazilian spatial inequalities, based on the analysis of the last three multiannual plans of the Federal Government (PPA 20042007, 2008-2011 and 2012-2015).

KeyWords: Planning; Inequality; Regional development; Multiannual plan.

\section{Introdução}

O contexto de fortes desigualdades regionais no Brasil tem origem em um processo histórico de uma ocupação territorial e uma dinâmica de ciclos econômicos regionalmente concentrados em algumas regiões do país. A partir do processo de industrialização e de integração do mercado nacional, ações do Estado e de agentes econômicos fortaleceram a concentração na região Sudeste.

As intervenções de caráter regional do Estado datam do final do século XIX, mas é a partir da década de 1930 que elas se intensificam, culminando com a montagem de um sistema de planejamento estatal durante o regime militar (1964-1985). As políticas foram direcionadas para a integração do mercado nacional e expansão da fronteira de valorização do capital para o interior do país, muitas vezes, sem levar em consideração as especificidades regionais no que se refere às reais necessidades da população.

A partir da promulgação da Constituição Federal de 1988, é inaugurado um novo ciclo na história do planejamento brasileiro. Se as décadas anteriores foram marcadas por uma trajetória instável da priorização do planejamento da ação pública, a Constituição trouxe a tentativa de resgate da iniciativa a longo prazo através da estruturação do Sistema de Planejamento e de Orçamento Federal. Nesse sentido, passou a competir a União dar provisões sobre os Planos Plurianuais (PPAs), as Leis de Diretrizes Orçamentárias (LDOs) e as Leis Orçamentárias Anuais (LOAs) e ao Congresso Nacional dispor sobre essas matérias (BRASIL, 1988; SILVA, 2014).

Durante a década de 1990 o país passou por um período de transição do paradigma social e econômico no país, de forma que as estruturas governamentais burocráticas e a figura estatal interventora foram deixadas de lado enquanto o neoliberalismo foi encontrando o seu caminho dentro dos instrumentos governamentais e, principalmente, nos de planejamento. Sendo assim, os três primeiros PPAs (1991-1995, 1996-1999 e 2000-2003) foram marcados pela orientação neoliberal, valorizando dentro das suas propostas medidcas como: incentivo a participação do setor privado nas ações nacionais, programas 
de desestatização, desregulamentação econômica, modernização produtiva e desenvolvimento de infraestrutura.

Em termos de planejamento territorial, o período foi caracterizado por um projeto orientado para a instrumentalização das regiões brasileiras em favor da elaboração de políticas que desenvolvam as suas respectivas potencialidades sob o viés competitivo global. Portanto, se durante as décadas de 1950 e 1960 a estratégia era baseada em termos de desenvolvimento social e econômico regional, a partir da década de 1990 o paradigma regional passa a ser orientado para a exploração das vantagens comparativas locais com vista a inserção competitiva do país no cenário internacional.

O custo dessa decisão política foi o aprofundamento das disparidades regionais e a marginalização das regiões que não tiveram condições de acompanhar a nova dinâmica competitiva nacional. Portanto, a experiência brasileira demonstra que a problemática regional surge de uma territorialização desigual do capitalismo e, consequentemente, do poder e, embora no discurso dos PPAs os governos se comprometem em reduzir as disparidades regionais, as políticas do Estado atuaram mais em seu fortalecimento do que na minoração dos efeitos da concentração desigual do capital no espaço.

Diante dessas considerações, o objetivo deste artigo é refletir sobre a responsabilidade do Estado em atuar na correção ou no fortalecimento das desigualdades produzidas pelo capital no território nacional, enfatizando as mudanças na sua dimensão territorial no período contemporâneo e tendo como base analítica a normatização dos Planos Plurianuais (PPAs).

É nesse sentido que as próximas seções deste artigo dedicam-se a avaliação documental e qualitativa dos três planos plurianuais recentes do Governo Federal (PPA 2004-2007; 20082011; 2012-2015) elaborados em um período de revitalização dos debates acerca da dimensão territorial do planejamento e de definição de uma nova estratégia de desenvolvimento regional para o país.

\section{O desenvolvimento regional na gestão Lula e Dilma}

A passagem do governo de Fernando Henrique Cardoso (1995-2002) para Luiz Inácio Lula da Silva (2003-2010) representa uma mudança na definição de novos rumos para o Brasil e inaugura um novo ciclo no planejamento regional brasileiro. A partir de 2003, o país passa a vivenciar um novo período de desenvolvimento baseado em estratégias contraditórias. Por 
um lado, não rompem por completo com o regime neoliberal, por outro, demonstram uma preocupação maior com a redução da pobreza e redistribuição de renda (através de políticas de valorização do salário mínimo, de transferência direta de renda, habitacional e outras).

O primeiro governo de Lula, apesar de controverso em relação à transição para uma trajetória pós-neoliberal, foi marcado por uma retomada da intervenção do Estado no domínio público, considerando-se os aumentos do porte de gastos e investimentos do governo. Nesse sentido, com a elaboração e institucionalização da Política Nacional de Desenvolvimento Regional (PNDR), alguns autores como Bernardo Campolina (2014) e Rezende (2010) afirmam que houve uma recuperação da dimensão espacial do desenvolvimento na agenda do Estado.

Os planos plurianuais analisados a seguir representam nos seus discursos uma definição bem clara da nova maneira de planejar adotada pelo governo. Apresentando uma maior estabilidade no que diz respeito ao comprometimento com a elaboração do PPA, serão treze anos de mudanças significativas relacionadas ao planejamento. Nesse sentido, através da análise do discurso dos planos, é possível identificar como a questão regional foi tratada ao longo desses anos e se, de fato, esses treze anos representam uma retomada do planejamento regional na agenda do Estado brasileiro.

\subsection{Plano Brasil de Todos (2004-2007)}

Durante os governos de Lula, a economia brasileira apresentou taxas de crescimento econômico mais elevadas do que as do período anterior, tais taxas foram sustentadas principalmente pelo contexto internacional favorável e aumento das exportações sob efeito da elevação da demanda chinesa ${ }^{1}$, articuladas às políticas macroeconômicas voltadas para a expansão do mercado interno - como, por exemplo, valorização do salário mínimo e expansão do crédito ao consumo (SIQUEIRA, 2015; PINTO, 2013).

Em relação aos impactos regionais desse crescimento econômico, Siqueira (2015) e Pinto (2013) concordam ao afirmar que esse teve um caráter desconcentrador. Consideram que, apesar de as políticas habitacionais, de valorização do salário mínimo, transferência direta de renda, infraestrutura e de valorização da agricultura familiar, por exemplo, não serem

\footnotetext{
${ }^{1}$ O Efeito China pode ser caracterizado pelo expressivo crescimento da demanda desse país, sob intensas taxas de crescimento, e seus impactos sobre a produção mundial de commodities, sobretudo na África e América Latina.
} 
efetivamente políticas regionais, elas tiveram impacto positivo na desconcentração regional da produção e do investimento.

Em termos de planejamento, o governo elaborou o PPA 2004-2007, Plano Brasil de Todos, com base em mega-objetivos de três dimensões, sendo elas:

a) Dimensão Social: apresenta intenções no sentido da inclusão social e redução das desigualdades sociais;

b) Dimensão Econômica, Ambiental e Regional: caracterizada através do intuito de promover um crescimento ambientalmente sustentável e com geração de emprego e renda, sem deixar de ter sua orientação voltada para a redução das desigualdades regionais; e

c) Dimensão Democrática: apresenta intenções no sentido da promoção e expansão da cidadania para o fortalecimento da democracia.

A previsão de distribuição de investimentos para o período de vigência do Plano Brasil de Todos concentra cerca de 63\% na Dimensão Social, comprometida com a inclusão e redução das desigualdades sociais (BRASIL, 2003).

A promoção da integração competitiva através do combate aos gargalos de infraestrutura permaneceu sendo um dos propósitos que movem o planejamento e a ação governamental, direcionando os seus esforços para a construção de uma base logística, energética e de telecomunicações capazes de aprimorar a complementaridade inter-regional brasileira e reduzir o custo de circulação da produção no território nacional.

Nesse sentido, a previsão de destinação de recursos da ordem de $\mathrm{R} \$ 189$ bilhões para infraestrutura - que correspondem a 32\% dos investimentos da dimensão econômica, ambiental e regional ${ }^{2}$ - confirma essa manutenção da estratégia de desenvolvimento do Estado via modernização dos pré-requisitos de mobilidade do capital, principalmente.

Em contraste aos anteriores, o PPA do primeiro governo Lula apresentou, em termos de política regional, uma preocupação com uma intervenção integrada das escalas de ação e planejamento. Entendendo que o ordenamento territorial não poderia passar apenas pela via de interesse do mercado, o plano traz o reconhecimento de que "as desigualdades sociais possuem uma dimensão regional e que seu enfrentamento passaria por uma nova política de desenvolvimento regional e o fortalecimento do planejamento territorial" (SILVA, 2014, p.171).

Em certa medida, o primeiro destaque do Plano Brasil de Todos seria esse reconhecimento da dimensão territorial das desigualdades sociais em seu discurso e, para isso, o plano

\footnotetext{
${ }^{2}$ Apesar do plano apresentar uma preocupação com a sustentabilidade e incluir a dimensão ambiental entre as suas estratégias, em termos de investimentos, a "questão meio ambiente" é alvo de menos de $1 \%$ dos recursos orçamentários destinados à dimensão da qual faz parte (BRASIL, 2003).
} 
identificava a necessidade do fortalecimento e reformulação da dimensão institucional desmontada anteriormente para a elaboração de um planejamento territorial comprometido com a redução das desigualdades regionais do país.

É crucial a adoção de instrumentos que permitam uma atuação do território visto de forma integrada e o equacionamento dos problemas das desigualdades sociais e econômicas dos espaços, numa perspectiva que abranja o conjunto do território nacional nas diversas escalas: nacional, macrorregional, sub-regional, local (BRASIL, 2003, p.101).

Se por um lado as regiões do país mais dinâmicas economicamente enfrentam problemáticas urbanas consequentes da expressiva aglomeração populacional nas grandes cidades, as regiões menos dinâmicas convivem com questões como, por exemplo, falta de acesso a direitos básicos e altos índices de pobreza. É nesse sentido que o PPA trouxe a proposta de uma política regional de "desenvolvimento solidário entre as regiões diversas do país", ou seja, rompe em certa medida com a política territorial centralizadora que marcou os governos anteriores e redireciona a mesma para uma escala nacional articulada com as subnacionais, com o objetivo de assegurar o crescimento econômico e social nas macrorregiões do país (BRASIL, 2003).

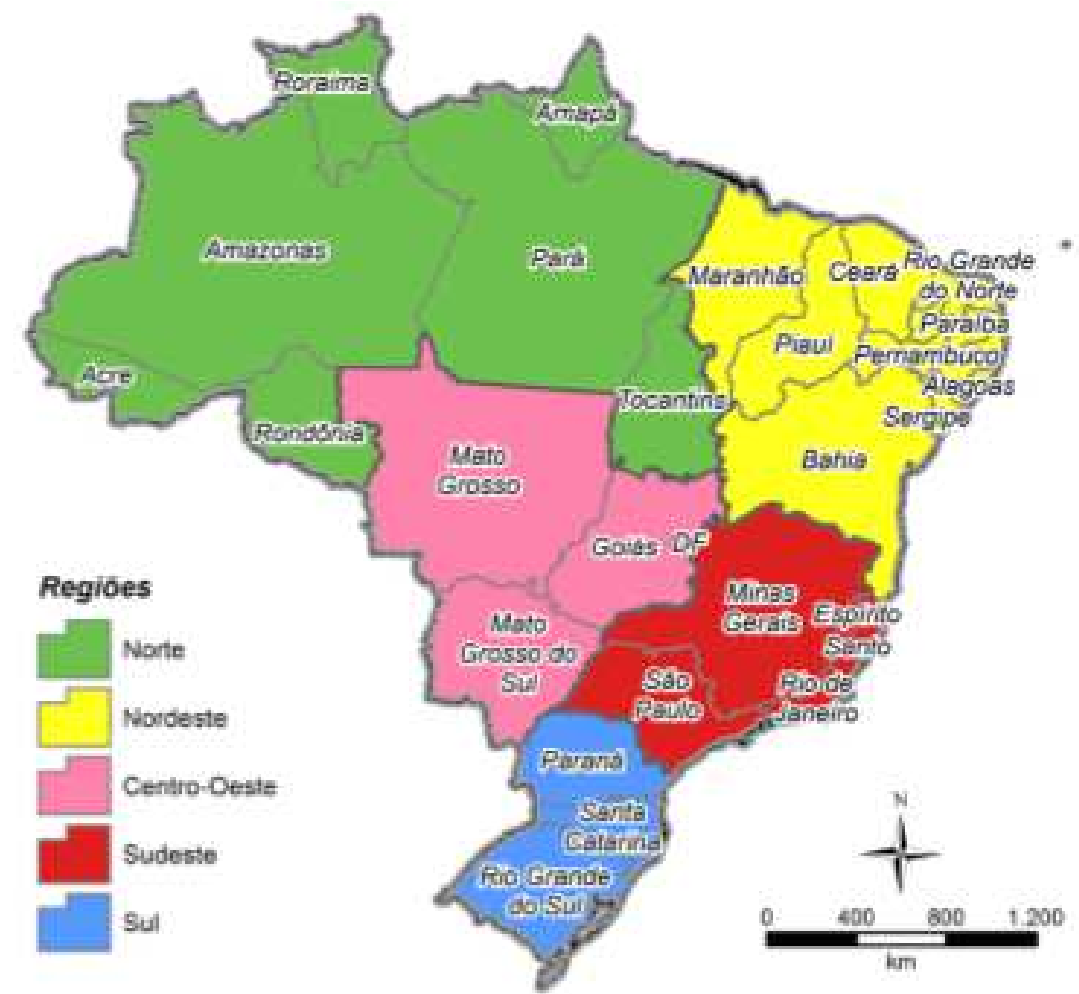

Figura 1 - Divisão Regional Brasileira - IBGE

Fonte: (SILVA, 2014). 


\subsubsection{Desconcentração regional do progresso técnico}

Dentro dos mais diversos desafios assumidos dentro do Plano Brasil de Todos, destaca-se a necessidade de "ampliar, desconcentrar regionalmente e fortalecer as bases científicas e tecnológicas de sustentação do desenvolvimento, democratizando o seu acesso". É nesse sentido que foram identificados alguns programas e ações no PPA que dizem respeito à promoção de um incentivo ao fortalecimento do vetor científico e tecnológico das regiões brasileiras, com vistas a minimizar o aumento dos desequilíbrios regionais, direcionados a temáticas que possam auxiliar na melhora da qualidade de vida da população local.

O Programa de Pesquisa e Desenvolvimento Científico e Tecnológico previsto no PPA teve a sua atuação direcionada no sentido do fortalecimento da pesquisa e aperfeiçoamento da infraestrutura tecnológica. Sob a direção do Ministério da Ciência e Tecnologia, foram investidos cerca de $15,74 \%$ do orçamento ministerial para a execução do programa conforme divulgado no Relatório de Avaliação dos Programas do PPA 2004-2007 (Ano Base 2007).

A criação do Centro de Estudos e Tecnologias Estratégicas para o Nordeste (CETENE) ocorreu em 2005 como uma das ações do Programa, tendo como missão o desenvolvimento de inovações tecnológicas de dimensão estratégica para o desenvolvimento econômico e social da região. O CETENE atua como articulador entre as temáticas de pesquisa a partir da identificação das necessidades locais, regionais e nacionais, assim como também oferece apoio ao desenvolvimento industrial e à agroindústria da região.

Outro exemplo de ação regionalizada do Programa na direção da desconcentração da atividade de pesquisa foi a criação, em 2004, do Instituto Nacional do Semiárido (INSA) ${ }^{3}$ como unidade de pesquisa vinculada ao Ministério da Ciência e Tecnologia. Um dos seus objetivos é a atividade de pesquisa e a formulação de políticas, com base nas potencialidades da região, para a promoção da coexistência sustentável na região do semiárido brasileiro (INSA, 2014).

O Programa Ciência e Tecnologia para Inclusão Social ${ }^{4}$ também chama a atenção dentro do PPA ao estabelecer como objetivo o incentivo a capacidade regional de gerar e difundir progresso técnico. Também sob direção do Ministério da Ciência e Tecnologia, foram investidos cerca de $3,11 \%$ do orçamento ministerial para a execução deste programa,

\footnotetext{
${ }^{3}$ O INSA tem projetos nas áreas de desertificação, gestão de recursos hídricos, manutenção da biodiversidade e desenvolvimento de tecnologias sociais geradas dentro da região, para a região (INSA, 2014).

${ }^{4}$ De acordo com o Relatório Anual de Avaliação dos Programas do Plano Brasil de Todos, o Programa Ciência e Tecnologia para a Inclusão Social teve alguns bons resultados, como a implantação do Instituto de Laticínio do Agreste no interior de Pernambuco, a implantação da Central de Reciclagem do Recife e a criação de uma incubadora de empreendimentos para o setor de confecções (BRASIL, 2007a).
} 
conforme o divulgado no Relatório de Avaliação dos Programas do PPA 2004-2007 (Ano Base 2007).

Algumas de suas ações são centradas no apoio a pesquisa e inovação para o desenvolvimento social na região Norte, fomento a capacitação tecnológica em setores de impacto social na região Nordeste, apoio a inovação tecnológica para o desenvolvimento local sustentável na região Norte, entre outras. Além disso, o programa também prevê ações de apoio a cadeias inter-regionais de ciência e tecnologia, porém, observa-se que, apesar dos exemplos citados, grande parte das ações do programa é de regionalização nacional.

É possível compreender, de certo modo, que o Plano Brasil de Todos avança no sentido de promover um movimento contrário a acumulação do progresso técnico nas regiões historicamente mais dinâmicas do país através da iniciativa de trazer a dimensão territorial para dentro da política de inovação tecnológica. Ou seja, diferencia-se das políticas assistenciais que marcaram décadas do planejamento regional brasileiro ao alinhar as potencialidades locais com a possibilidade de pesquisas e desenvolvimento de inovações tecnológicas que, além de contribuírem para minimização da dependência tecnológica externa, também agem no sentido de modernizar a capacidade de desenvolvimento das regiões menos dinâmicas.

Em certo sentido, se antes a capacidade competitiva das regiões Norte e Nordeste possuíam vantagens comparativas de menor valor agregado dentro desse sistema de fluxo de capitais e comercialização internacional, a difusão e o aperfeiçoamento do progresso técnico nessas regiões podem constituir uma maneira de romper essa barreira.

\subsubsection{O desafio da modernização da infraestrutura brasileira}

Diante dos desafios reconhecidos no âmbito do PPA 2004-2007, outro que merece destaque é a necessidade de "impulsionar os investimentos em infraestrutura de forma coordenada e sustentável". Nesse sentido, ele representa a inclinação do governo em direção a modernização e expansão da infraestrutura do país com o objetivo de impactar na redução dos custos de circulação da produção no território e atuar na melhoria da distribuição social e regional de renda.

O desafio da infraestrutura abrange um cenário extenso, que vai desde a temática do transporte até a da comunicação. Porém, apesar do Plano Brasil de Todos abordar esses temas, aqui será destacada a temática dos recursos hídricos, que apresenta programas regionalizados de enfrentamento à adversidade climática em determinadas regiões do país. 
Sob a direção do Ministério da Integração Nacional, o programa Desenvolvimento Integrado e Sustentável do Semi-Árido (CONVIVER) foi previsto no PPA com o objetivo de reduzir a vulnerabilidade socioeconômica da região do semi-árido com incidência de seca. Sendo alvo de investimentos de cerca de $7,74 \%$ do orçamento ministerial para a sua execução, o CONVIVER previa ações como, por exemplo, a ampliação do abastecimento de água, gerenciamento de recursos hídricos, estruturação e organização de arranjos produtivos locais, apoio a Projetos de Desenvolvimento Sustentável Local Integrado no Semi-Árido, implantação do Polo de Desenvolvimento na Região do Cariri, entre outros.

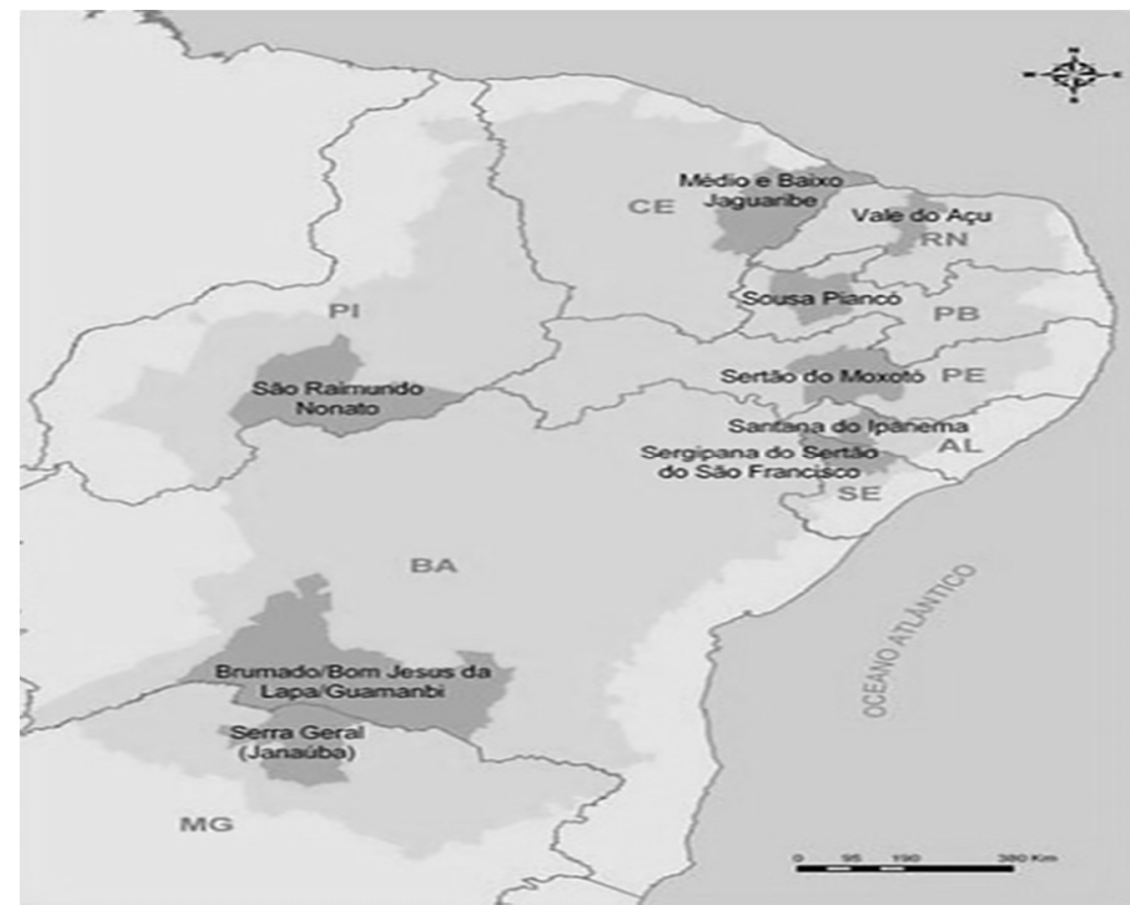

Figura 2 - Sub-regiões prioritárias do programa CONVIVER Fonte: (MINISTÉRIO DA INTEGRAÇÃO NACIONAL, 2009)

Além disso, o programa também previa a atuação na formação e capacitação de recursos humanos e promoção de acesso a direitos básicos como saúde, educação e saneamento, o que exigia um fortalecimento da articulação interministerial para a sua execução.

Segundo o divulgado nos Relatórios Anuais de Avaliação dos Programas do PPA, os resultados do CONVIVER durante o período (2004-2007) foram promissores:

Apoio a quatro projetos para a estruturação de arranjos produtivos locais (APL), definidos e viabilizados por meio de articulações com os governos Estaduais, Municipais e sociedade civil organizada: a) ovinocultura, na sub-região de Serra Geral - (Janaúba - (MG); b) estudos e pesquisa sobre o pinhão-manso para a produção de biodiesel, também na Serra Geral; c) piscicultura, com a implantação de unidade de beneficiamento de peixe, no Município de Jurema (PI); d) apoio à 
fruticultura, com a implantação de agroindústria, em Brumado (BA), na sub-região de Brumado (BA), Bom Jesus da Lapa (BA) e Guanambi (BA) (BRASIL, 2007a, p.846).

\subsubsection{A redução das desigualdades regionais}

Além dos desafios citados nas seções anteriores, vale destacar o reconhecimento da necessidade de "reduzir as desigualdades regionais e intra-regionais com integração das múltiplas escalas espaciais, estimulando a participação da sociedade no desenvolvimento local". Reconhecendo a importância da atuação do governo na materialização diferenciada do capital no território através da concentração produtiva e de infraestrutura tecnológica, este desafio trata especificamente da desigualdade regional, procurando enfrentar a questão através de programas regionais específicos.

Nesse sentido, o programa Promoção da Sustentabilidade de Espaços Sub-regionais (PROMESO) é previsto com o objetivo de aumentar a autonomia e sustentabilidade dos espaços sub-regionais através do aproveitamento e valorização das especificidades locais e fortalecimento das suas respectivas bases produtivas (BRASIL, 2003).

O destaque do programa é certamente a sua dimensão escalar. Inovando com relação às iniciativas de planejamento territorial anteriores, o PROMESO revela um comprometimento do Plano Brasil de Todos com a atuação integrada em novas escalas espaciais dando preferência para a sub-regional. É nesse sentido que o Ministério da Integração Nacional admite a necessidade do PROMESO enquanto iniciativa que representa o reconhecimento da importância da atuação na escala sub-regional no processo de interiorização e desconcentração do crescimento econômico regional, inserindo de forma social e econômica as populações locais (BRASIL, 2005).

Resumidamente, o PROMESO, que antes teria sido reservado ao ostracismo no governo de Fernando Henrique Cardoso, nesse momento apresentou resultados expressivos no que diz respeito ao apoio a mais de quarenta arranjos produtivos locais e no fortalecimento institucional dos fóruns e comitês gestores dos mesmos (BRASIL, 2005). 


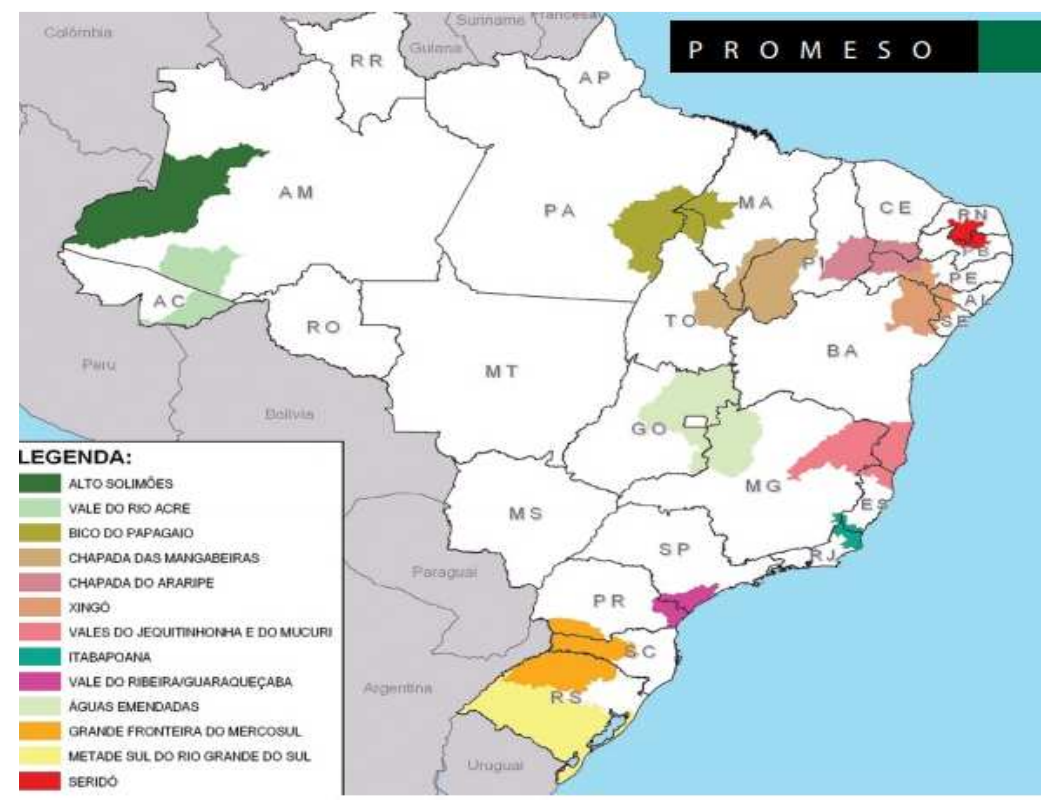

Figura 3 - Sub-regiões prioritárias do programa PROMESO Fonte: (MINISTÉRIO DA INTEGRAÇÃO NACIONAL, 2009b).

Além do PROMESO, o PPA 2004-2007 trouxe a previsão do programa Promoção e Inserção Econômica de Sub-regiões (PROMOVER). Também sob direção do Ministério da Integração Nacional, o programa atua na mesma percepção escalar sub-regional integrada, porém com um viés mais voltado para a integração competitiva desses territórios. As ações são principalmente centradas em dois eixos gerais: apoio a arranjos produtivos locais e capacitação de recursos humanos para a competitividade. Porém, em meio a sua execução, foi realizada uma mudança estratégica na atuação do programa, de forma que as suas ações foram incorporadas aos outros programas de base territorial como o PROMESO, CONVIVER e o Programa de Desenvolvimento Social da Faixa de Fronteira (BRASIL, 2007a).

Em termos de avaliação, cabe destacar que todos os programas do Plano Brasil de Todos citados nas seções anteriores enfrentaram dificuldades muito semelhantes que, historicamente, já fazem parte da implementação de políticas públicas brasileiras e continuam carecendo de uma atenção maior. Os programas relacionados ao progresso técnico-científico revelaram grande dificuldade no que diz respeito a deficiência de recursos humanos disponíveis na parte executora das ações, o que, exige uma ação de médio prazo para a formação, capacitação e contratação de agentes públicos que possam atuar na ponta da política.

Além disso, todos os programas citados anteriormente possuíram deficiência expressiva no monitoramento e acompanhamento das ações e projetos executados, seja sob a alegação de insuficiência de recurso para arcar com despesas administrativas ou pela incapacidade de 
elaboração de indicadores efetivos, grande parte dos programas tiveram a sua avaliação comprometida e os seus índices não foram medidos, o que acabou por impossibilitar uma avaliação mais complexa sobre o nível do impacto dessas ações e, possivelmente, impossibilitam ou dificultam uma análise dos pontos fracos que precisam ser remodelados para o seu próximo ciclo de implementação.

Apesar do discurso deste PPA apresentar o Plano como um valorizador da intervenção multiescalar e uma maior articulação entre os entes federativos, os relatórios anuais de avaliação do PPA revelam que os programas de base territorial aqui citados tiveram uma interação deficitária entre si, assim como a aplicação de recursos das respectivas ações foram realizadas de maneira desarticulada, dificultando a mensuração dos impactos nas áreas prioritárias apoiadas pelos programas (BRASIL, 2006).

Por último, vale considerar que, apesar dessas questões, não se pode desvalidar o fato de que o PPA 2004-2007 representa o rompimento com décadas de desinteresse do Estado no que diz respeito à consideração da dimensão espacial dentro do planejamento público. Seja através da previsão desses programas ou da formulação da Política Nacional de Desenvolvimento Regional (PNDR) ${ }^{5}$, é possível perceber que o primeiro governo Lula traz uma revitalização dos debates acerca do planejamento territorial dentro do âmbito estatal e representa alguns avanços em relação ao período anterior.

\subsection{Plano Plurianual (2008-2011)}

Durante o segundo governo Lula manteve-se no PPA (2008-2011) boa parte das diretrizes que marcaram o plano anterior. A estratégia de desenvolvimento permanece na direção da manutenção de um círculo virtuoso de crescimento através da expansão de consumo e, ao menos a nível de discurso, a redução das desigualdades regionais aparece como uma das prioridades para viabilizar o projeto de desenvolvimento do PPA (2008-2001), intitulado Plano Desenvolvimento com Inclusão Social e Educação de Qualidade.

\footnotetext{
${ }^{5}$ Embora a Política Nacional de Desenvolvimento Regional tenha representado uma mudança de paradigma importante em relação ao histórico brasileiro de política nacional de desenvolvimento regional, por uma questão de delimitação temática não é possível tratar da complexidade total do tema ainda neste artigo. Porém, é importante ressaltar que ela nasce da necessidade de redefinição de uma nova regionalização do território nacional para que as políticas de desenvolvimento regional estivessem adequadas ao dinamismo econômico, político e social em nível subnacional, superando os limites e problemas de integração históricos; e tem como plano geral de ação o investimento em infraestrutura e a promoção da inclusão da população no processo de desenvolvimento. Para mais detalhes: Ler "OLIVEIRA, F; WERNER, D. Perspectiva histórica do planejamento regional no Brasil. In: CEPAL - Coleção Documentos de Projetos, 2013”.
} 
Portanto, ao destacar o território como um elemento determinante ao projeto de desenvolvimento, no seu discurso, o plano o reconhece não apenas como provedor passivo de insumos ao desenvolvimento, mas também como "estruturas sócio-espaciais ativas nas quais o ambiente socioeconômico e os traços histórico-culturais e sócio-geográficos sejam decisivos para o sucesso ou o fracasso de qualquer desenvolvimento" (BRASIL, 2007c, p.13). Em termos da dimensão territorial, a mensagem do plano traz uma valorização da escala sub-regional e local para a execução dos seus programas e ações, justificando essa incorporação com objetivos como, por exemplo, o fortalecimento da unidade territorial, a inserção competitiva no contexto global e o aproveitamento dos potenciais de desenvolvimento das diversas regiões (BRASIL, 2007c).

Com a previsão de investimentos da ordem de, aproximadamente, $R \$ 3$. 525,6 bilhões, o PPA 2008-2011 foi estruturado em três agendas prioritárias, são elas: Agenda Social, Plano de Desenvolvimento da Educação (PDE) e Programa de Aceleração do Crescimento (PAC). Com investimentos previstos somando cerca de $\mathrm{R} \$ 540,3$ bilhões, por mais que não constitua uma política de ordem territorial diretamente, a área social foi situada dentro de um contexto territorial que prevê programas para a área rural com o objetivo de suscitar a superação dos níveis de pobreza e as oportunidades de emprego e renda através de uma intervenção com foco no território.

Nesse sentido, o Programa Nacional de Agricultura Familiar (PRONAF) constitui um exemplo de iniciativas do PPA que unem a inclusão produtiva das populações em situação de vulnerabilidade com ações de acesso à cidadania e qualificação de assentamentos. Sob administração do Ministério da Agricultura, o programa tem por objetivo o fortalecimento da agricultura familiar através da promoção da inserção competitiva no mercado produtivo. Presente desde o Plano Brasil de Todos, ele retorna com a previsão de metas de investimentos da ordem de $\mathrm{R} \$ 2,4$ milhões até 2011 , tendo como exemplo de ações o suporte ao desenvolvimento de empreendimentos de agricultores familiares no Nordeste brasileiro.

Além disso, a agenda do PPA traz políticas sociais que, ao longo do tempo, apresentaram rebatimentos territoriais expressivos. Com a previsão de dispêndios da ordem de $R \$ 11$ milhões até o final da vigência do PPA, o Programa Bolsa Família aparece com o maior número de beneficiados distribuídos na região Nordeste, que possui o maior número de famílias pobres.

De acordo com o divulgado pelo Palácio do Planalto, em maio de 2015, o número de famílias beneficiadas pelo programa ainda apresentava grande concentração na região 
Nordeste. Com isso, o Bolsa Família representa um exemplo do rebatimento territorial que as políticas sociais adotadas durante o governo Lula obtiveram.

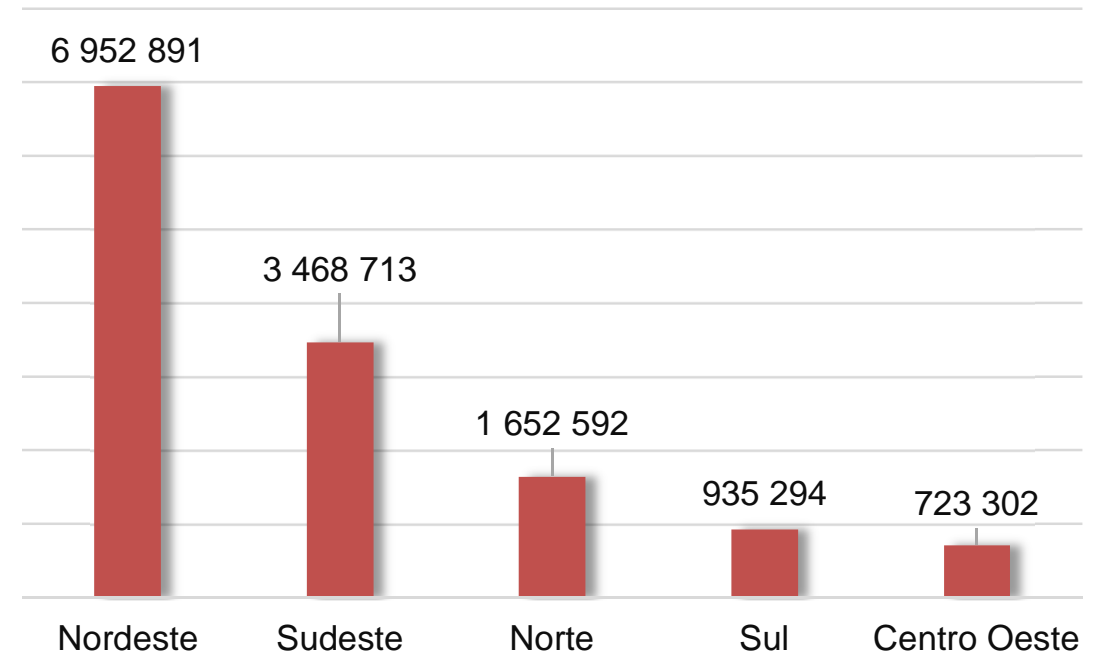

Gráfico 1. Famílias beneficiárias do Programa Bolsa Família em 2015, por macrorregião.

Fonte: (BRASIL, 2015d) - Elaborado pela autora.

A mensagem presidencial do PPA 2008-2011 também apresenta uma série de objetivos do governo para o período. A título de interesse deste artigo, cabe destacar dois desses desafios assumidos pelo Presidente. O primeiro deles é o reconhecimento da necessidade de "implantar uma infraestrutura eficiente e integradora do território nacional". Nesse ponto, o plano traz o entendimento de que o investimento e aperfeiçoamento da infraestrutura brasileira correspondem a um dos pontos essenciais para a superação dos desequilíbrios regionais, mantendo uma tendência de manifestação dessa preocupação dentro dos planos plurianuais que se estende desde o governo de Fernando Henrique Cardoso (PPA 1996-1999).

Portanto, principalmente na área de transportes, o objetivo seria superar as limitações históricas de infraestrutura e expandir cada vez mais em direção ao interior do país. Diante disso, o discurso com relação aos efeitos sociais dessa consternação com a infraestrutura caminha na direção da

\footnotetext{
${ }^{6}$ Porém, vale destacar que durante o governo Lula - e, de certa forma, durante a gestão de Fernando Henrique Cardoso - a preocupação com a infraestrutura brasileira revela uma mudança de paradigma quanto a sua mensuração em relação ao período da ditadura militar, por exemplo. Se antes se tratava de uma questão geopolítica (ocupação do território), nesse momento ela também é objeto de uma questão geoeconômica, voltada para a otimização dos fluxos de bens e serviços (SILVA, 2014). Entretanto, durante o governo de Fernando Henrique Cardoso esses investimentos não foram concretizados, de fato.
} 
[...] condução de investimentos específicos para a redução de desigualdades regionais em áreas deprimidas, e para a integração do continente sul-americano. A ampliação da cobertura geográfica será relevante para induzir o desenvolvimento em áreas de expansão da fronteira agrícola e mineral (BRASIL, 2007c, p.91).

Dessa forma, o plano traz uma integração entre a infraestrutura nacional com a redução das desigualdades espaciais ao prever, através do PAC, grandes intervenções em infraestrutura nas regiões Norte, Nordeste e Centro Oeste, reconhecendo que a malha consolidada de transporte, energia e comunicações ainda é concentrada nas regiões Sul e Sudeste do país (BRASIL, 2007c).

O segundo desafio do plano consiste em "reduzir as desigualdades regionais a partir das potencialidades locais do território nacional". Uma das prioridades é a necessidade de incentivo à desconcentração produtiva como essencial para o processo de interiorização do desenvolvimento brasileiro, distribuindo regionalmente o crescimento econômico cada vez mais e promovendo condições de acesso a direitos básicos ainda deficitários nas regiões menos dinâmicas do país.

Porém, ainda que um dos objetivos do governo tenha sido pautado pela desconcentração produtiva, um fenômeno importante deve ser destacado no que diz respeito ao caráter dessa interiorização. A grosso modo, observa-se o deslocamento de indústrias tradicionais (calçados e vestuário, por exemplo) - que não exigem mão de obra muito qualificada - para a região Nordeste, enquanto a concentração da indústria pesada e de maior progresso técnico continuam se concentrando nos grandes centros do Sudeste e Sul (SABOIA; KUBRUSLY, 2008).

Entretanto, de acordo com Silva (2014), o PAC configura-se como a grande base desse PPA, sendo responsável pela elevação do nível de investimento em infraestrutura de forma expressiva. Com uma carta de investimentos extensa nos setores de transportes, recursos hídricos, energia, saneamento e habitação, o PAC representa a retomada do poder de investimento do Estado em níveis significativos, além de também prever medidas de estímulo ao crédito e ao financiamento, desoneração tributária e melhoria do ambiente de investimento (BRASIL, 2007c).

Buscando a superação dos gargalos na infraestrutura logística e energética, os investimentos do PAC seguiram na direção de promover um ambiente favorável para a expansão do mercado interno e a expansão da capacidade produtiva do país, totalizando a previsão de investimentos, para o período até 2010, da ordem de $\mathrm{R} \$ 503,9$ bilhões distribuídos entre as regiões Norte, Nordeste, Sul, Sudeste e Centro Oeste. 
Porém, por mais que o aporte de recursos do Programa se concentrasse de forma expressiva na região Sudeste, enquanto aliado a políticas de ampliação de crédito, transferência de renda e valorização do salário mínimo, o PAC teve um rebatimento territorial importante no crescimento econômico das regiões Norte e Nordeste ${ }^{7}$. Ou seja, por mais que essas políticas não fossem políticas regionais stricto sensu, elas tiveram impactos significativos nas regiões de menor PIB do país.

Além disso, o PPA 2008-2011 mantém os programas de desenvolvimento como o PROMESO e o CONVIVER que estavam presentes no plano anterior, além de reconhecer a necessidade de integração das políticas públicas de ordem territorial que, como foi visto anteriormente, representaram uma das dificuldades na execução desses programas durante a vigência do Plano Brasil de Todos.

Diante desse balanço sobre as principais ações referentes à dimensão territorial durante os dois mandatos de Lula, vale a pena questionar até que ponto essa dimensão foi de fato incorporada na formulação e implementação do planejamento no primeiro decênio dos anos 2000. Por mais que os estudos apontem para um significativo impacto na configuração do desenvolvimento regional brasileiro e, no início da primeira gestão de Luís Inácio Lula da Silva, a questão regional tenha sido considerada como uma das prioridades dentro da agenda do Estado, essa tendência foi se esvaziando ao longo do tempo.

\subsection{Plano Mais Brasil (2012-2015)}

Se durante os dois mandatos do Presidente Lula o cenário era de revitalização dos debates acerca da dimensão territorial do planejamento, ao longo do tempo esse ímpeto foi perdendo força e, apesar das taxas de crescimento das regiões Norte (5,2\%) e Nordeste (5\%) se apresentarem acima da média nacional (4,6\%) durante o período 2004-2011 configurando uma tendência mínima de abatimento da desigualdade regional brasileira -, elas foram, em grande medida, reflexo de um rebatimento territorial das políticas sociais adotadas (SIQUEIRA, 2013).

Dentro de um contexto de crescimento econômico do país aliado a uma estratégia nacional de distribuição de renda e mitigação das desigualdades sociais, Dilma Rousseff foi eleita em 2010 com o desafio de consolidar e dar continuidade aos significativos avanços dos oito anos anteriores, além de propor novos caminhos para o desenvolvimento nacional.

\footnotetext{
${ }^{7}$ A previsão da construção da Ferrovia Transnordestina é um exemplo de ações do PAC com impacto no desenvolvimento regional, tendo em vista que o PPA apresenta a ferrovia como a constituição de uma "nova fronteira de desenvolvimento para o semi-árido nordestino" (BRASIL, 2007c, p.21).
} 
É nesse sentido que o discurso do Plano Mais Brasil assume o desafio de manter o padrão do ciclo de desenvolvimento e aperfeiçoar os mecanismos de distribuição de renda e redução da pobreza, além de, em termos econômicos, trazer a ambição de elevar a competitividade da economia brasileira e promover a sua inserção ativa na economia mundial. Para tal feito, a elaboração do Plano Mais Brasil foi baseada na definição de onze macro-desafios que iriam orientar as políticas públicas do Governo Federal durante quatro anos. À título de interesse desse trabalho, destacam-se dois desafios, são eles: o Projeto Nacional de Desenvolvimento e Erradicação da Pobreza.

O Projeto Nacional de Desenvolvimento foi constituído com o objetivo de apoiar o processo de desenvolvimento que havia se estruturado nos últimos anos através da redução das desigualdades regionais e transformação produtiva com distribuição de renda. Ações de desenvolvimento local como economia solidária e os arranjos produtivos locais foram considerados como essenciais para a conquista deste desafio.

Além disso, a integração das políticas industrial, tecnológica e de comércio exterior se revelou como uma das prioridades dentro do projeto nacional de desenvolvimento, evidenciando uma preocupação do governo em orientar o desenvolvimento da nação através do viés da inserção ativa do Brasil no cenário competitivo global e, para isso, foi prevista a necessidade de aprimoramento da articulação intersetorial e atuação conjunta da tríade Estado - sociedade - setor privado.

O desafio da Erradicação da Pobreza foi fundamentado com o objetivo de eliminar o cenário de pobreza extrema e reduzir as desigualdades sociais. Nesse sentido, o Plano Brasil Sem Miséria ${ }^{8}$ surgiu como alternativa de superação desse grande obstáculo, articulando ações que vão para além da garantia mínima de renda, incluindo também um sistema de apoio que oferece as bases necessárias para a emancipação do indivíduo através da promoção de ações na área de acesso a serviços públicos e inclusão produtiva.

Levando em consideração que "[...] do ponto de vista regional, mais de $70 \%$ das pessoas com renda domiciliar per capita abaixo de $1 / 4$ de salário mínimo estão nas regiões Nordeste e Norte" (BRASIL, 2011a, p.36), o governo de Dilma Rousseff dá prosseguimento ao expressivo

\footnotetext{
${ }^{8}$ Vale considerar que, até o período de elaboração do PPA, 16 milhões de brasileiros ainda se encontravam em um contexto de extrema pobreza e cerca de $60 \%$ dessa população estava concentrada na região Nordeste. De forma que políticas de combate à miséria, como esse exemplo, acabam por ter impacto implícito na mitigação da configuração desigual do desenvolvimento no território (BRASIL, 2011a).
} 
investimento nas políticas sociais como uma estratégia de desenvolvimento regional implícita, sendo o Plano Brasil Sem Miséria um exemplo claro dessa tendência 9 .

Sob a coordenação do Ministério do Desenvolvimento Social e em parceria com 22 ministérios, estados e municípios, o Plano Brasil Sem Miséria foi responsável pela retirada de aproximadamente 22 milhões de brasileiros da linha de extrema pobreza e a sua relação com o PPA $2012-2015^{10}$ foi considerável, ao prever metas desde a oferta de cursos de qualificação profissional até a distribuição de sementes para plantio para beneficiários do plano (BRASIL, 2015c).

A estratégia do plano é centrada na valorização de avanços tecnológicos, investimentos do setor público, exploração sustentável dos recursos hídricos e intensificação das relações de comércio, além de traçar novas perspectivas regionais para o país (BRASIL, 2011a).

A perspectiva regional para o período é sustentada em alguns aspectos fundamentais, são eles:

a) Aumento da expressão relativa das regiões Norte e Nordeste através do aprofundamento da sua produção no setor de produtos agrícolas e minerais ${ }^{11}$

b) Geração de empregos de qualidade para tornar o mercado de trabalho mais igualitário e;

c) Interiorização de instituições federais de ensino, propondo em certo nível uma articulação do desenvolvimento regional através da relação entre especialização produtiva, formação de recursos humanos e avanços tecnológicos (BRASIL, 2011a).

Outro aspecto fundamental e que constitui condição para a convergência de condições econômicas e sociais entre as regiões, acompanhada da tendência à interiorização, é a educação, determinante para a inclusão social, a efetivação de direitos, a inovação, as atividades econômicas intensivas em conhecimento e a formação de mão de obra nos vários níveis. Nesse sentido, a expectativa é que o cenário de desenvolvimento produtivo com ampliação das oportunidades mais bem distribuídas ao longo do território brasileiro se realizará a partir da associação entre fomento à produção, à inovação e à educação, aplicadas às bases produtivas locais, aumentando os gastos nessas áreas e gerando dinâmicas econômicas e sociais virtuosas (BRASIL, 2011a, p.61).

\footnotetext{
${ }^{9}$ A delimitação do público-alvo do plano influencia diretamente no cenário de configuração da desigualdade regional brasileira ao levar em consideração que $59 \%$ dos seus beneficiários estão concentrados na região Nordeste (BRASIL, 2013).

${ }^{10}$ O Plano Brasil Sem Miséria foi contemplado no PPA por diversos programas, alguns deles são: Agricultura Familiar, Biodiversidade, Energia Elétrica, Segurança Alimentar e Nutricional e o de Fortalecimento do Sistema Único de Assistência Social (BRASIL, 2011b).

${ }^{11} \mathrm{O}$ cenário externo de expansão da demanda internacional e valorização do preço das commodities constitui um dos principais fatores que influenciam nessa definição de estratégia de dinamização dessas regiões. Além disso, essa orientação para o setor agrícola e de exploração mineral representa um contraste interessante à estratégia adotada durante os governos do Lula, que priorizou por um desenvolvimento mais orientado para o viés sustentável e de progresso técnico-científico nas regiões de menor PIB.
} 
Se em 2002 o país tinha cerca de 43 campi de universidades federais implantados, em termos de execução, a estratégia de interiorização dos institutos federais de ensino teve impacto positivo ao ser responsável pela expansão desse número para 230 campi em 2010, desconcentrados nas regiões de menor PIB do país e em direção ao interior (ARAÚJO, 2013). Além disso, sendo destacado como uma política que teve expressiva contribuição para a redução das desigualdades regionais na gestão anterior, o PPA (2012-2015) apresenta o programa Territórios da Cidadania (PTC), criado em 2008, como outra alternativa de política com recorte territorial a ser considerada novamente para o período.

Ao diagnosticar "[...] que havia baixo acesso a serviços básicos, estagnação na geração de renda e carência de políticas integradas e sustentáveis que possibilitassem autonomia econômica de médio prazo para os trabalhadores rurais" (BRASIL, 2011a, p.275), o programa surgiu com o objetivo de transformar esse cenário e promover a superação da pobreza no meio rural através de uma estratégia de desenvolvimento territorial. Sob a direção do Ministério do Desenvolvimento Agrário, o objetivo do PTC é atuar com uma cooperação interministerial e federativa para a promoção da articulação de diversas políticas públicas setoriais para a área rural.

De acordo com o Decreto de 25 de fevereiro de 2008, a atuação do programa é estruturada em três eixos: infraestrutura, atividades produtivas e cidadania e direitos. Através do programa, em 2008, 60 territórios rurais foram atendidos e mais tarde, em 2009, a abrangência foi ampliada para 120 territórios.

Em termos gerais, a infraestrutura permanece sendo considerada como fator estratégico para a homogeneização territorial do desenvolvimento através da segunda fase do PAC (2011-2014), estabelecendo como alguns dos seus objetivos a integração dos polos produtivos das regiões Norte e Centro Oeste com as demais e a uniformização territorial da oferta de serviços ligados a energia, recursos hídricos e infraestrutura produtiva.

O PAC 2 vem com propostas ainda mais ambiciosas contando com a previsão de investimentos da ordem de mais de R\$ 900 bilhões para o intervalo 2011-2014 e, aproximadamente, mais de R\$ 620 milhões para o período pós-2014. Nesse momento, o programa concentrou a sua primazia no setor de energia, logística e em seu novo eixo de infraestrutura social e urbana, tendo como destaque o programa "Minha Casa, Minha Vida" e o "Água e Luz para Todos" que democratizou e levou a oferta de serviços para áreas que não possuíam acesso aos serviços básicos (IPEA, 2010).

Ademais, trata-se também do planejamento urbano no que diz respeito à necessidade de promover e aperfeiçoar a oferta de serviços como saneamento básico, mobilidade urbana e 
moradia, entendendo que políticas desse tipo são essenciais para a superação das desigualdades sociais e territoriais e melhoria da qualidade de vida das populações urbanas (BRASIL, 2011a).

De maneira geral, se nos discursos dos dois planos plurianuais do governo Lula era apontada uma prioridade da política regional dentro da agenda governamental, através dessa análise foi possível compreender o processo de substituição de políticas regionais "explícitas" pela articulação de políticas sociais e de investimento em infraestrutura ocorrido durante o governo Dilma.

Por mais que a primazia tenha sido dedicada, principalmente, à agenda social e aos investimentos do Programa de Aceleração do Crescimento em detrimento do estabelecimento de uma estratégia regional explícita, não se pode ignorar os impactos positivos na redução da pobreza através das políticas de transferência direta de renda e de valorização do salário mínimo, como o programa Bolsa Família e os benefícios de prestação continuada, por exemplo. A seguir, a Tabela 1 mostra esse impacto através da queda percentual de pessoas de baixa renda, segundo as macrorregiões brasileiras.

\begin{tabular}{|c|c|c|c|c|c|c|c|}
\hline & 2003 & 2004 & 2005 & 2006 & 2007 & 2008 & 2009 \\
\hline Região Norte & & & & & & & \\
\hline Menor que 1/2 SM & 59,7 & 58,6 & 55,5 & 50,7 & 50,5 & 44,9 & 44,5 \\
\hline Menor que 1/4 SM & 28,4 & 27,7 & 24,2 & 20,4 & 21,5 & 17,1 & 17,2 \\
\hline Região Nordeste & & & & & & & \\
\hline Menor que 1/2 SM & 71,2 & 69,4 & 65,5 & 60,4 & 58,7 & 54,4 & 52,4 \\
\hline Menor que 1/4 SM & 43,9 & 39,7 & 35,1 & 30,5 & 29,1 & 25,4 & 23,8 \\
\hline Região Sudeste & & & & & & & \\
\hline Menor que 1/2 SM & 34,7 & 32,6 & 28,7 & 24,6 & 23,9 & 21 & 19,6 \\
\hline Menor que 1/4 SM & 13,3 & 11,3 & 9,1 & 7,2 & 7,4 & 6,1 & 5,8 \\
\hline Região Sul & & & & & & & \\
\hline Menor que 1/2 SM & 31,7 & 28,9 & 21,2 & 22,9 & 21,2 & 19 & 17,7 \\
\hline Menor que 1/4 SM & 11,4 & 9,9 & 8,5 & 6,8 & 6,6 & 5,5 & 5,1 \\
\hline Região Centro Oeste & & & & & & & \\
\hline Menor que 1/2 SM & 43 & 38,5 & 36,5 & 31,2 & 30,1 & 25,7 & 24,4 \\
\hline Menor que 1/4 SM & 17,3 & 13,5 & 12 & 9,2 & 8,9 & 7,5 & 7 \\
\hline
\end{tabular}

Tabela 1. Percentual (\%) de pessoas de baixa renda (2003-2009), por macrorregiões brasileiras Fonte: (SIQUEIRA, 2014).

Em termos produtivos, como pode ser visto na Tabela 2, não ocorreram grandes alterações na distribuição regional do PIB, as regiões Sul e Sudeste permanecem sendo responsáveis por maior parte da produção nacional. Nesse sentido, a ausência de uma estratégia nacional explícita de desenvolvimento regional aliada à concentração dos investimentos da indústria pesada (hidrelétricas, química, exploração de petróleo) no litoral do país, permanecem 
constituindo um empecilho ao avanço significativo na desconcentração produtiva (SIQUEIRA, 2015).

\begin{tabular}{|c|c|c|c|c|c|c|c|c|c|}
\hline Macrorregiões & 2002 & 2003 & 2004 & 2005 & 2006 & 2007 & 2008 & 2009 & 2010 \\
\hline Norte & 4,7 & 4,8 & 4,9 & 5 & 5,1 & 5 & 5,1 & 5 & 5,3 \\
\hline Nordeste & 13 & 12,8 & 12,7 & 13,1 & 13,1 & 13,1 & 13,1 & 13,5 & 13,5 \\
\hline Sudeste & 56,7 & 55,8 & 55,8 & 56,5 & 56,8 & 56,4 & 56 & 55,3 & 55,4 \\
\hline Sul & 16,9 & 17,7 & 17,4 & 16,6 & 16,3 & 16,6 & 16,6 & 16,5 & 16,5 \\
\hline Centro-Oeste & 8,8 & 9 & 9,1 & 8,9 & 8,7 & 8,9 & 9,2 & 9,6 & 9,3 \\
\hline
\end{tabular}

Tabela 2. Distribuição regional da participação no PIB, por macrorregiões Fonte: (IBGE, 2010) - Elaborado pela autora.

Sendo assim, o mais recente período do planejamento regional brasileiro se mostrou, em grande medida, contraditório. Na medida em que os avanços sociais se mostram expressivos no que diz respeito à redução da pobreza e a expansão do acesso ao mercado de consumo, os interesses do capital financeiro e do agronegócio exportador permanecem como prioridade na janela de conciliação do governo Dilma.

\section{Conclusão}

A análise bibliográfica revelou a permanência da importância do investimento público como principal vetor de ação para a superação dos obstáculos ao desenvolvimento nacional. A trajetória recente da dimensão territorial no planejamento governamental brasileiro evidencia que, embora a redução das desigualdades regionais seja uma determinação constitucional, o planejamento e as ações estatais às vezes são direcionados para a materialização dos interesses do capital, mesmo que os impactos de tais ações possam influenciar no aumento das desigualdades espaciais brasileiras. 
Nesse sentido, a dualidade entre intenções e princípios constitucionais e a execução de políticas públicas de fato revela a multiplicidade de interesses de classes e frações de classes que constituem o Estado enquanto matéria. Sendo assim, a partir dessa compreensão, vale a insistência no debate acerca da necessidade de disputa pela arena política decisória e do papel do Estado e do território no modelo de desenvolvimento capitalista.

A experiência de redução da intervenção estatal no domínio social e econômico na década de 1990 trouxe graves consequências para o país e revelou a limitação do projeto neoliberal de desenvolvimento. Através da retomada do Estado como indutor do desenvolvimento econômico, a experiência do período pós-2003 expressou como a mínima mudança na arena política é capaz de trazer impactos no direcionamento da política social e regional, de modo que trouxe à tona a importância da atuação estatal na superação de gargalos e na minoração de desigualdades territoriais e, principalmente, sociais que ficam no rastro de reprodução do capitalismo.

Embora a experiência do último decênio tenha demonstrado considerável avanço nesse sentido, a permanência da concentração do PIB na região Sudeste do país mostra que a questão da concentração produtiva brasileira permanece sendo um fenômeno a ser superado. Ou seja, por mais que a implementação de políticas sociais e de renda tenham influenciado na distribuição de renda, isso não foi o suficiente para atingir os problemas estruturais de desigualdade econômica entre as regiões do país.

A problemática regional brasileira possui um caráter estrutural, de modo que apenas políticas de rebatimento territorial não se mostram suficientes para trazer uma alteração de grande impacto no quadro de desigualdade regional brasileira. Nesse sentido, por mais que em alguns momentos a questão regional tenha figurado dentro da agenda governamental, ela "[...] não reuniu forças suficientes para tornar-se uma prioridade e obter recursos e apoio político para a reconstrução da institucionalidade requerida e para a implementação de seus programas e ações" (SILVA, 2014, p.198).

Portanto, é necessário que haja uma transformação nas estruturas produtivas regionais, de forma que as regiões mais pobres sejam capazes de sustentar o desenvolvimento das suas estruturas produtivas e, consequentemente, garantir a sustentabilidade dos avanços sociais já em voga. Para tal feito, torna-se mais do que urgente a elaboração de uma política 
nacional de desenvolvimento regional que tenha expressividade, de fato, na agenda de prioridades do governo. Uma vez estando as políticas setoriais articuladas, os investimentos em programas sociais mantidos e o compromisso firmado com a política nacional de desenvolvimento regional será possível iniciar os passos na direção da transformação estrutural do quadro regional brasileiro.

Embora diversos autores apontem para a necessidade de articulação dessas questões enquanto uma estratégia de Estado para a superação das desigualdades regionais, a mais recente ofensiva neoliberal que ocorre no país desde o processo (sic) de impeachment de Dilma Rousseff (2011-2016) representa uma ameaça às estratégias que foram adotadas ao longo dos últimos treze anos e a possibilidade de avanços na estruturação de uma agenda política regional consolidada.

Em termos regionais, com base na análise histórica a qual esse trabalho se propôs é possível prever que a possibilidade de retrocesso quanto à definição de políticas de desenvolvimento regional e ordenamento territorial e as chances de aprofundamento das desigualdades regionais é muito próxima de uma realidade futura.

\footnotetext{
Carlos Brandão (informação verbal) observa que, num contexto de crescimento econômico, não se coloca a questão regional como uma pauta importante na agenda governamental, lembrando que entre 2006 e 2010 houve grande crescimento da economia nacional; por outro lado, quando não há crescimento econômico, a questão regional não entra na pauta política pois não há espaço para questões estruturais devido à ênfase dada aos problemas conjunturais. Assim, a questão regional não avança espontaneamente em nenhum cenário (SILVA, 2014, p.195).
}

Através de propostas de congelamento dos gastos públicos e reforma previdenciária empreendidos pelo governo de Michel Temer, grande parte do que foi construído ao longo desses anos em termos de planejamento regional, apesar dos seus limites, é alvo de sérias ameaças.

Portanto, é importante permanecer afirmando que a expansão do investimento público é fundamental não somente para ampliar a sua oferta de bens e serviços, como também para dar prosseguimento ao estímulo do dinamismo nacional. Se o governo Lula, durante a crise mundial de 2008, apostou nas políticas anticíclicas e na expansão do investimento como estratégia para a proteção e manutenção do aquecimento da economia nacional, acreditar que uma política de congelamento de investimentos, como a que o governo atualmente 
propõe, é pagar um preço socioeconômico muito alto para ver as tentativas liberais serem frustradas novamente.

\section{Referências bibliográficas}

ARAÚJO, T. B. Tendências do Desenvolvimento Regional Recente no Brasil. In: BRANDÃO, C. A.; SIQUEIRA, H. O. (Orgs.). Pacto federativo, integração nacional e desenvolvimento regional. São Paulo: Ed. Fundação Perseu Abramo, 2013, p.39-51. Disponível em: < http://www.fpabramo.org.br/ >. Acesso em: dezembro, 2016.

BRASIL. Constituição da República Federativa do Brasil de 1988. Brasil: Brasília, DF, 5. Out. 1988. Disponível em: < http://www.planalto.gov.br/ccivil 03/Constituicao/Constitui\%C3\%A7ao.htm >. Acesso em: setembro, 2016.

BRASIL. Decreto de 25 de fevereiro de 2008. Institui o Programa Territórios da Cidadania e dá outras providências. Diário Oficial da União, Brasília, DF, 26 fev. 2008. Disponível em: < http://www.planalto.gov.br/ccivil 03/ Ato2007-2010/2008/Dnn/Dnn11503.htm >. Acesso em: dezembro, 2016.

BRASIL. Decreto no 2.829, de 29 de outubro de 1998. Estabelece normas para a elaboração e execução do Plano Plurianual e dos Orçamentos da União, e dá outras providências. Diário Oficial da União, Brasília, DF, 29 out. 1998. Disponível em: < http://www.planalto.gov.br/ccivil 03/decreto/D2829.htm >. Acesso em: outubro, 2016.

BRASIL. Ministério do Desenvolvimento Social - MDS. Plano Brasil Sem Miséria. Caderno de resultados 20112014. Brasília, 2015c. Disponível em: < http://www.mds.gov.br/ >. Acesso em: novembro, 2016.

BRASIL. Ministério da Integração Nacional - MI. Programa de Desenvolvimento Integrado e Sustentável do Semi-Árido (CONVIVER). Cartilha do Programa CONVIVER. Brasília, 2009. Disponível em: < http://www.integracao.gov.br/ >. Acesso em: outubro, 2017.

BRASIL. Ministério da Integração Nacional - MI. Programa de Promoção da Sustentabilidade de Espaços Subregionais (PROMESO). Cartilha do Programa PROMESO. Brasília, 2009b. Disponível em: < http://www.integracao.gov.br/ >. Acesso em: outubro, 2017.

BRASIL. Ministério do Planejamento, Orçamento e Gestão - MPOG. Plano Plurianual 2004-2007. Anexo II (Programas de governo). Brasília, 2003. Disponível em: < http://www.planejamento.gov.br/ >. Acesso em: novembro, 2016.

BRASIL. Ministério do Planejamento, Orçamento e Gestão - MPOG. Plano Plurianual 2004-2007. Relatório anual de avaliação (ano base 2004). Brasília, 2005. Disponível em: < http://www2.camara.leg.br/atividadelegislativa/orcamentobrasil/ppa/ppa2004 7.html/avaliacao >. Acesso em: novembro, 2016.

BRASIL. Ministério do Planejamento, Orçamento e Gestão - MPOG. Plano Plurianual 2004-2007. Relatório anual de avaliação (ano base 2005). Brasília, 2006. Disponível em: < http://www2.camara.leg.br/atividadelegislativa/orcamentobrasil/ppa/ppa2004 7.html/avaliacao >. Acesso em: novembro, 2016.

BRASIL. Ministério do Planejamento, Orçamento e Gestão - MPOG. Plano Plurianual 2004-2007. Relatório anual de avaliação (ano base 2006). Brasília, 2007a. Disponível em: < http://www2.camara.leg.br/atividadelegislativa/orcamentobrasil/ppa/ppa2004 7.html/avaliacao >. Acesso em: novembro, 2016.

BRASIL. Ministério do Planejamento, Orçamento e Gestão - MPOG. Plano Plurianual 2012-2015. Anexo I (Programas temáticos). Brasília, 2011b. Disponível em: < http://www.planejamento.gov.br/ >. Acesso em: dezembro, 2016. 
BRASIL. Ministério do Planejamento, Orçamento e Gestão - MPOG. Secretaria de Planejamento e Investimentos Estratégicos. Plano Plurianual 2004-2007: Mensagem Presidencial. Brasília, $2003 . \quad$ Disponível em: < http://www2.camara.leg.br/atividade-legislativa/orcamentobrasil/ppa/ppa2004 7.html >. Acesso em: novembro, 2016.

BRASIL. Ministério do Planejamento, Orçamento e Gestão - MPOG. Secretaria de Planejamento e Investimentos Estratégicos. Plano Plurianual 2008-2011: Mensagem Presidencial. Brasília, 2007c. Disponível em: < http://www2.camara.leg.br/atividade-legislativa/orcamentobrasil/ppa/ppa-2008-2011 >. Acesso em: novembro, 2016.

BRASIL. Ministério do Planejamento, Orçamento e Gestão - MPOG. Secretaria de Planejamento e Investimentos Estratégicos. Plano Plurianual 2012-2015: Mensagem Presidencial. Brasília, 2011a. Disponível em: < http://www2.camara.leg.br/atividade-legislativa/orcamentobrasil/ppa/ppa-2012-2015 >. Acesso em: dezembro, 2016.

BRASIL. Palácio do Planalto. Bolsa Família repassa R\$ 2,3 bilhões para quase 50 milhões de brasileiros. Brasília, 2015d. Disponível em: < http://www2.planalto.gov.br/noticias >. Acesso em: dezembro, 2016.

BRASIL. Palácio do Planalto. Brasil sem Miséria reúne medidas de transferência de renda, acesso a serviços e inclusão produtiva para 16,2 milhões de brasileiros. Brasília, 2013. Disponível em: < http://www2.planalto.gov.br/ >. Acesso em: novembro, 2016.

CAMPOLINA, Bernardo. O planejamento regional e urbano no Brasil. Revista Política e Planejamento Regional, Rio de Janeiro, v.1, n.2, p.345-348, jul./dez. 2014. Disponível em: < http://www.revistappr.com.br/>. Acesso em: setembro, 2016.

CENTRO DE TECNOLOGIAS ESTRATÉGICAS PARA O NORDESTE - CETENE. Apresentação. Recife, 2011. Disponível em: < http://www.cetene.gov.br/ >. Acesso em: dezembro, 2016.

INSTITUTO DE PESQUISA ECONOMICA APLICADA. As bases do novo desenvolvimento brasileiro - a reorganização do Estado. In: Perspectivas do desenvolvimento brasileiro - livro 10. Brasília: Ipea, 2010, p.39-56.

INSTITUTO DE PESQUISA ECONOMICA APLICADA. Rebatimentos regionais da retomada do desenvolvimento. In: Perspectivas do desenvolvimento brasileiro - livro 10. Brasília: Ipea, 2010, p.95-110.

INSTITUTO NACIONAL DO SEMIÁRIDO - INSA. Institucional. Paraíba, 2014. Disponível em: < http://www.insa.gov.br/ >. Acesso em: dezembro, 2016.

PINTO, E. C. Dinâmica econômica e regional no Brasil dos Anos 2000: efeito China, desconcentração espacial e bloco no poder. In: BRANDÃO, C. A.; SIQUEIRA, H. O. (Orgs.). Pacto federativo, integração nacional $e$ desenvolvimento regional. São Paulo: Ed. Fundação Perseu Abramo, 2013, p. 87-102. Disponível em: < http://www.fpabramo.org.br/ >. Acesso em: outubro, 2016.

REZENDE, F. Planejamento no Brasil: auge, declínio e caminhos para a reconstrução. Textos para Discussão CEPAL - IPEA, n.4, 2010, p.1-31. Disponível em: < http://repositorio.ipea.gov.br/ >. Acesso em: outubro, 2016.

SABOIA, J.; KUBRUSLY,L. Diferenciais regionais e setoriais na indústria brasileira. Revista Economia Aplicada, v.12, no1, jan./mar. 2008. Disponível em: < http://www.revistas.usp.br/ >. Acesso em: dezembro, 2016.

SILVA. Simone Affonso da. O planejamento regional brasileiro pós-Constituição Federal de 1988: instituições, políticas e atores. pg.44-247. 518 f. Dissertação (Mestrado) - Faculdade de Filosofia, Letras e Ciências Humanas, Universidade de São Paulo, São Paulo, 2014.

SIQUEIRA, H. O. Desigualdades Regionais e Pacto Federativo no Brasil. In: LIMONAD, E.; CASTRO, E. R. (Org.). Um novo planejamento para um novo Brasil?. Rio de Janeiro: Ed. Letra Capital, 2014, p. 149-162.

SIQUEIRA, H. O.. Dinâmica Regional Brasileira (1990-2012). In: BRANDÃO, C. A.; SIQUEIRA, H. O. (Orgs.). Pacto federativo, integração nacional e desenvolvimento regional. São Paulo: Ed. Fundação Perseu Abramo, 2013, p.73-86. Disponível em: < http://www.fpabramo.org.br/ >. Acesso em: outubro, 2016.

SIQUEIRA, H. O.. O Novo desenvolvimentismo e dinâmica urbano-regional no Brasil (2004-2012). Revista EURE, v.41, n. 122, p.261-277, 2015. 